\title{
ATIVIDADE ALELOPÁTICA E CITOTÓXICA DO EXTRATO AQUOSO DE ESPINHEIRA-SANTA (MAYTENUS ILICIFOLIA MART. EX REISS.)
}

\author{
ALLELOPATHIC AND CYTOTOXIC ACTIVITY OF THE AQUEOUS \\ EXTRACT OF MAYTENUS ILICIFOLIA MART. EX REISS.
}

\author{
Sérgio Alessandro Machado Souza ${ }^{1^{*}}$, Letícia Vesz Cattelan ${ }^{1}$, \\ Daiane Peixoto Vargas ${ }^{1}$, Clause Fátima de Brum Piana ${ }^{2}$, \\ Vera Lucia Bobrowski ${ }^{1}$, Beatriz Helena Gomes Rocha ${ }^{1}$ \\ 1* Autor para contato: Universidade Federal de Pelotas - UFPel, Instituto de Biologia, \\ Departamento de Zoologia e Genética, Laboratório de Genética, Pelotas, RS, Brasil; \\ (53) 3275-7138; e-mail: sergiobioufpel@yahoo.com.br \\ 2 Universidade Federal de Pelotas - UFPel, Departamento de Fitotecnia, Pelotas, RS
}

Recebido para publicação em 18/08/2005

Aceito para publicação em 25/01/2006

\section{RESUMO}

O monitoramento de fitoquímicos com propriedades potencialmente tóxicas pode ser avaliado por alterações fisiológicas e celulares do organismo-teste exposto. O presente estudo teve como objetivo avaliar o potencial alelopático e citotóxico do extrato aquoso de espinheira-santa (Maytenus ilicifolia) sobre sementes de alface e de cebola. Os bioensaios foram conduzidos em germinador $\left(20^{\circ} \mathrm{C}\right)$, com extrato aquoso nas concentrações de $5,10,20$ e $40 \mathrm{mg} / \mathrm{mL}$, obtido por infusão de folhas secas, e água destilada (controle). Os testes de germinação, primeira contagem e índice de velocidade de germinação, que avaliam efeito alelopático, foram feitos com quatro repetições de 100 sementes/concentração/ bioensaio. Para determinação da citotoxicidade, através do índice mitótico, foram contadas, pela técnica de varredura, 2000 células/concentração/bioensaio. As células de meristema radicular de cebola, quando expostas ao extrato aquoso de folhas de M. ilicifolia na concentração de $40 \mathrm{mg} / \mathrm{mL}$, apresentaram alterações cromossômicas, sugerindo um potencial genotóxico. Conclui-se que o extrato aquoso de espinheira-santa apresenta efeito alelopático sobre sementes de alface ( que pode ser explicado pela presença de saponinas, taninos e flavonas) e também efeito citotóxico sobre sementes de alface e de cebola.

Palavras-chave: alelopatia, divisão celular, fitotoxicidade, genotoxicidade 


\begin{abstract}
The monitoring of phytochemicals with potentially toxic properties can be evaluated through alterations, at physiological and cellular levels, of the exposed test organism. The present study aimed to evaluate the allelopathic and cytotoxic activity of the aqueous extract of Maytenus ilicifolia on lettuce and onions seeds. Bioassays were carried out in a germinator at $20^{\circ} \mathrm{C}$ with aqueous extracts in concentrations of 5, 10, 20 and $40 \mathrm{mg} / \mathrm{mL}$, obtained through the infusion of dried leaves and distilled water (control). The germination tests, first score and germination speed rate that evaluate the allelopathic effect were done with four repetitions of 100 seeds/concentration/bioassay. For the determination of the degree of cytotoxicity, through the mitotic index, 2000 cells/concentration/bioassay were scored by means of the scan technique. Onion root meristematic cells when exposed to $M$. ilicifolia leaf aqueous extract at a concentration of $40 \mathrm{mg} / \mathrm{mL}$, showed chromossomal alteration, suggesting the existence of a genotoxic potential. The aqueous extract of $M$. ilicifolia displayed an allelopathic effect on lettuce seeds (which can be explained by the presence of saponins, tannins and flavones) as well as a cytotoxic effect on lettuce and onion seeds.
\end{abstract}

Key words: allelopathy, cell division, phytotoxicity, genotoxicity

\section{Introdução}

O termo alelopatia foi criado em 1937 pelo pesquisador alemão Hans Molisch, com a reunião das palavras gregas alléton (mútuo) e pathos (prejuízo), referindo-se a capacidade que as plantas têm de interferir na germinação de sementes e no desenvolvimento de outras, por meio de substâncias que essas liberam na atmosfera ou, quase sempre, no solo (Medeiros, 1990). Esse efeito é realizado por biomoléculas, denominadas aleloquímicos, produzidas e lançadas por plantas como substâncias gasosas volatilizadas no ar que as cercam (Ferreira e Aquila, 2000).

As substâncias alelopáticas são produtos intermediários ou finais do metabolismo secundário (Rodrigues e Lopes, 2001). Constituem também uma forma de comunicação, pois permitem às plantas distinção entre os organismos que lhes são prejudiciais, benéficos ou, até mesmo, indiferentes (Almeida, 1993). Segundo Ferreira e Aquila (2000), os compostos aleloquímicos foram de extrema importância à evolução vegetal, pois ofereceram alguma vantagem contra a ação de microrganismos, vírus, insetos e outros patógenos ou predadores, inibindo ou estimulando a ação e o crescimento destes, bem como o desenvolvimento das plantas.

Há, aproximadamente, 10 mil produtos químicos conhecidos como alelopáticos, pertencentes a vários grupos de substâncias (Rodrigues e Lopes, 2001). As substâncias químicas mais comuns causadoras de efeitos alelopáticos pertencem aos grupos dos ácidos fenólicos, cumarinas, terpenóides, flavonóides, alcalóides, glicosídeos, cianogênicos, derivados do ácido benzóico, taninos e quinonas complexas (Medeiros, 1990).

Os compostos químicos, muitas vezes considerados como alelopáticos, são utilizados na medicina popular para a cura de doenças. A preparação e o uso apropriados desses compostos trazem muitos benefícios, porém, seus efeitos genotóxicos e mutagênicos necessitam de maiores investigações (Nunes e Araujo, 2003). Atualmente, a maioria das pesquisas em alelopatia refere-se ao efeito aleloquímico sobre a germinação e o crescimento da planta-teste, não considerando os efeitos celulares relacionados às suas mudanças fisiológicas (Prates et al., 2001).

A citotoxicidade e a genotoxicidade de substâncias pode ser avaliada, respectivamente, através 
de alterações no processo de divisão celular sobre o organismo-teste e pela incidência de mutações cromossômicas, como quebras cromatídicas, pontes anafásicas, perda de cromossomos inteiros ou formação de micronúcleos (Souza et al., 2005).

Segundo Chou e Kuo (1986), a fitotoxicidade de extratos vegetais sobre outras plantas é atribuída à diversidade de aleloquímicos presentes em sua composição, originados do metabolismo secundário dos vegetais.

A espinheira-santa (Maytenus ilicifolia Mart. ex Reiss.), pertencente à família Celastraceae, é uma espécie perene, de porte arbóreo-arbustivo sendo encontrada nativa na região sul do Brasil, no interior de matas nativas e ciliares, onde os solos são ricos em matéria orgânica (Magalhães, 2002).

$\mathrm{O}$ interesse medicinal mais comum pela espinheira-santa é para o tratamento de gastrites e úlceras gástricas e duodenais (Lorenzi, 2002). Faleiros (1992), quando estudou frações hexânicas de espinheira-santa, evidenciou que os compostos presentes em grande quantidade são triterpernos como friedelina e friedelanol, sendo esses os responsáveis pelo efeito antiulcerogênico.

Para a constatação do efeito alelopático e citotóxico de substâncias, o procedimento inicial consiste na técnica do bioensaio, que emprega material biológico como indicador da ação da substância em estudo (Pires et al., 2001). A resistência ou tolerância aos compostos químicos que podem atuar desencadeando efeitos alelopáticos ou citotóxicos é mais ou menos específica, existindo espécies mais sensíveis que outras, como, por exemplo, alface (Lactuca sativa L.) e tomate (Lycopersicum esculentum L.) (Ferreira e Aquila, 2000).

Visto que as sementes são excelentes organismos para bioensaios, pois quando são reidratadas entram em processo de germinação, sofrendo rápidas mudanças fisiológicas e tornando-se altamente sensíveis ao estresse ambiental, o presente estudo teve como objetivo avaliar o potencial alelopático e citotóxico do extrato aquoso de espinheira-santa sobre sementes de alface (Lactuca sativa L.) e de cebola (Allium cepa L.).

\section{Material e métodos}

O presente trabalho foi realizado no Laboratório de Genética do Departamento de Zoologia e Genética do Instituto de Biologia da Universidade Federal de Pelotas - RS.

\subsection{Extrato aquoso}

Para a obtenção dos extratos aquosos foram utilizadas folhas secas de espinheira-santa, que foram pesadas em balança de precisão e colocadas em erlenmeyer $(500 \mathrm{~mL})$. Após, foi adicionada água destilada à temperatura de $100^{\circ} \mathrm{C}$ nos recipientes, os quais foram hermeticamente fechados e deixados em repouso por 10 minutos. Após filtragem, o extrato aquoso obtido foi diluído de modo a obter-se quatro concentrações do extrato vegetal $(5,10,20$ e $40 \mathrm{mg} / \mathrm{mL})$.

\subsection{Bioensaio}

Os organismos-testes utilizados foram sementes de alface cultivar Rainha de Maio e de cebola cultivar Baia Periforme Precoce, sendo que as sementes de alface foram submetidas a resfriamento de $4^{\circ} \mathrm{C}$ por $72 \mathrm{~h}$ para superação da dormência. Os bioensaios foram realizados em câmara de germinação com temperatura controlada de $20^{\circ} \mathrm{C}$. As sementes de alface e cebola foram acondicionadas em caixas gerbox $(11 \times 11 \mathrm{~cm})$ forradas com papel mata-borrão umedecido com 10 $\mathrm{mL}$ do extrato, de cada uma das quatro concentrações. Foi utilizado também um tratamento controle, equivalente à concentração zero do extrato, onde o papel mata-borrão foi umedecido com água destilada. Foram utilizadas quatro repetições de 100 sementes para cada uma das cinco concentrações do extrato, totalizando 20 caixas gerbox por bioensaio.

Para o teste de primeira contagem, a avaliação foi realizada aos quatro dias para a alface e aos seis dias para a cebola; para o teste de germinação ou germinabilidade, a contagem foi aos sete dias para alface e aos doze para a cebola; e para o índice de velocidade de germinação foram realizadas contagens 
diárias, segundo as regras para análise de sementes (Brasil, 1992).

\section{3. Índice mitótico}

Para a determinação do índice mitótico foi empregada a técnica de esmagamento (Guerra e Souza, 2002). Foram coletadas as radículas dos organismostestes e fixadas em Carnoy (3:1, etanol: ácido acético) por um período de $24 \mathrm{~h}$ à temperatura ambiente e, após, acondicionadas em freezer. A preparação do material para posterior análise do índice mitótico foi realizada na seguinte ordem: água destilada por 5 minutos; $\mathrm{HCl} 5 \mathrm{~N}$ por 15 minutos à temperatura ambiente; água destilada por 5 minutos. Após, as radículas foram transferidas para lâmina onde em microscópio esteroscópico foi retirada a coifa para a obtenção do meristema apical, adicionada orceína acética $2 \%$, colocada uma lamínula sobre o material esmagado. As lâminas das células de alface e de cebola foram observadas em microscópio óptico a uma magnitude de 400x.

Foram contadas, em teste cego, através da técnica de varredura, 2000 células por tratamento para cada bioensaio. O índice mitótico foi obtido dividindose o número de células em mitose pelo número total de células observado e multiplicando-se por 100.

\subsection{Caracterização de fitoquímicos}

Nesta análise qualitativa, o extrato foi preparado separadamente. Pó das folhas secas, na concentração de $5 \%(\mathrm{p} / \mathrm{v})$, foi mantido em banho-maria fervente por 15 minutos. Após esse período, seguiu-se o resfriamento e a filtragem do extrato. Foram escolhidos apenas três grupos de metabólitos secundários, as saponinas, os taninos e os flavonóides, por serem solúveis em água. Para a realização de cada teste, foi colocada uma pequena quantidade dos extratos $(5 \mathrm{~mL})$ em tubos de ensaio, de acordo com a seguinte metodologia (Silva, 2004):

- Saponinas - para detectar a presença destas moléculas, foi empregado o teste de formação e persistência de espuma estável na presença de ácidos minerais diluídos. Os extratos nos tubos seguiram as seguintes operações: agitação enérgica por 10 segundos (para cima e para baixo, com vigor), tapandose o tubo com dedo-protegido; medição da altura do anel formado, logo após a agitação, 10 minutos depois da agitação e após a adição de ácido clorídrico $10 \%$.

- Taninos - foi empregada a reação de precipitação com gelatina para a detecção destes metabólitos secundários, não sendo realizadas, contudo, diferenciações entre os taninos condensados e os hidrolisáveis. Foram adicionadas ao extrato três gotas de gelatina $1 \%$. Na presença de taninos, a gelatina precipita, tornando a solução turva.

- Flavonóides - neste teste foi empregada à reação com cianidina. Adicionou-se ao extrato $5 \mathrm{~mL}$ de metanol e $1 \mathrm{~mL}$ de $\mathrm{HCl}$ concentrado, observandose a coloração formada. Após, colocou-se $100 \mathrm{mg}$ de magnésio em pó. O desenvolvimento de coloração avermelhada indica a presença predominante de flavonóis e a coloração laranja, a de flavonas.

\subsection{Análise estatística}

O delineamento experimental foi completamente casualizado, com quatro repetições, e os tratamentos foram arranjados em esquema fatorial $2 \times 5$, sendo os fatores Bioensaio (Alface e Cebola) e Concentração $(0,5,10,20$ e $40 \mathrm{mg} / \mathrm{mL})$.

As variáveis analisadas foram: primeira contagem, germinação, índice de velocidade de germinação e índice mitótico. A unidade experimental consistiu de uma caixa gerbox com 100 sementes, para as variáveis primeira contagem, germinação e índice de velocidade de germinação, e uma lâmina onde foram observadas 500 células (totalizando 2000 células em quatro lâminas) para a variável índice mitótico. As variáveis primeira contagem, germinação e índice mitótico foram transformadas segundo arco seno de $\sqrt{\mathrm{x} / 100}$.

As análises estatísticas consistiram de análise da variação e regressão polinomial para a decomposição da variação atribuível ao fator Concentração. $\mathrm{Na}$ regressão, além da significância dos efeitos dos componentes polinomiais $(p<0,05)$, foi utilizado o coeficiente de determinação $\left(\mathrm{R}^{2}\right)$ como critério adicional 
para escolha do modelo. Essas análises foram executadas pelo programa WinStat - Sistema de Análise Estatística para Windows - Versão Beta (Machado e Conceição, 2005).

\section{Resultados e Discussão}

Os resultados das análises de variação, proce- didas para as variáveis primeira contagem, germinação, índice de velocidade de germinação e índice mitótico, estão sumariados na tabela 1 . Verifica-se que o efeito principal de Bioensaio e a interação Bioensaio x Concentração foram significativos para todas as variáveis. A significância da interação justificou o estudo do efeito simples do fator Concentração, que é o de maior interesse, dentro de cada nível do fator Bioensaio, o qual foi realizado por meio de análise de regressão polinomial.

Tabela 1 - Principais resultados das análises da variação e testes de significância para as variáveis primeira contagem (PC), germinação (GE), índice de velocidade de germinação (IVG) e índice mitótico (IM).

\begin{tabular}{|c|c|c|c|c|c|c|c|c|c|}
\hline \multirow[t]{2}{*}{ Fonte de variação } & \multirow[t]{2}{*}{ G } & \multicolumn{2}{|c|}{ PC $(\%)$} & \multicolumn{2}{|c|}{ GE $(\%)$} & \multicolumn{2}{|l|}{ IVG } & \multicolumn{2}{|c|}{ IM (\%) } \\
\hline & & $\mathrm{QM}^{*}$ & Prob.** & $\mathrm{QM}^{*}$ & Prob.** & $\mathrm{QM}^{*}$ & Prob.** & QM* & Prob.** \\
\hline Bioensaio & 1 & $7.582,7$ & 0,0463 & $11.123,5$ & 0,0063 & $30.656,7$ & 0,0044 & $1.074,18$ & 0,0211 \\
\hline Concentração & 4 & 669,2 & 0,6221 & 371,4 & 0,5309 & 978,1 & 0,4743 & 311,00 & 0,1066 \\
\hline Bioensaio x Conc. & 4 & 932,2 & 0,0000 & 403,4 & 0,0000 & 913,3 & 0,0000 & 79,05 & 0,0000 \\
\hline Resíduo & 30 & 35,7 & & 42,4 & & 71,6 & & 7,70 & \\
\hline \multicolumn{2}{|l|}{ Média geral } & \multicolumn{2}{|c|}{52,81} & \multicolumn{2}{|c|}{60,88} & \multicolumn{2}{|c|}{39,45} & \multicolumn{2}{|c|}{25,32} \\
\hline \multicolumn{2}{|l|}{ CV (\%) } & \multicolumn{2}{|c|}{11,31} & \multicolumn{2}{|c|}{10,70} & \multicolumn{2}{|c|}{21,45} & \multicolumn{2}{|c|}{10,96} \\
\hline
\end{tabular}

* Quadrado médio

** Probabilidade

Para o bioensaio alface, as curvas de regressão, apresentadas na figura 1, mostram que o modelo de grau dois (quadrático) foi o que melhor representou a relação entre a concentração do extrato de espinheirasanta e cada uma das variáveis analisadas.

Em relação às variáveis primeira contagem, germinação e índice de velocidade de germinação, os valores cresceram até concentrações ao redor de 10 $\mathrm{mg} / \mathrm{mL}$. Isto indica que os constituintes presentes no extrato aquoso de espinheira-santa, até essa concentração, não foram fitotóxicos para as sementes de alface (Figura 1A, 2B e 1C). Segundo Rice (1984), alguns compostos têm atividade alelopática inibitória em altas concentrações, mas, em menores, podem não estimular o mesmo processo.

O extrato de espinheira-santa teve efeito citotóxico sobre as células de meristemas radiculares da alface, o que pode ser observado na curva de regressão que exibe a redução do índice mitótico com o aumento da concentração do extrato (Figura 1D). Górnick et al. (1997) verificaram que a germinação de sementes de repolho (Brassica oleracea L.) não estava relacionada com a taxa de divisão celular, visto que as sementes germinavam na presença de inibidores mitóticos.

Para o bioensaio cebola, verificou-se que o extrato de espinheira-santa não teve efeito significativo sobre as variáveis primeira contagem, germinação e índice de velocidade de germinação. Com relação ao índice mitótico, o modelo que melhor explicou o efeito do extrato sobre esta variável foi o de grau dois (quadrático), cuja curva de regressão é apresentada na figura 2. Observa-se que os valores do índice mitótico decresceram até concentração próxima de $30 \mathrm{mg} / \mathrm{mL}$. 


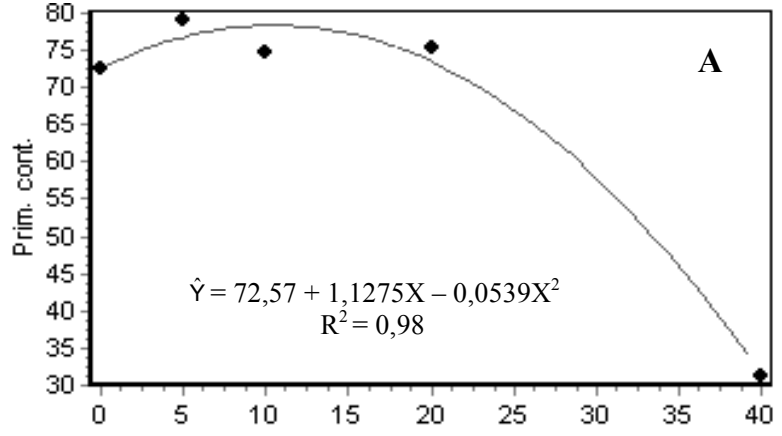

Concentração

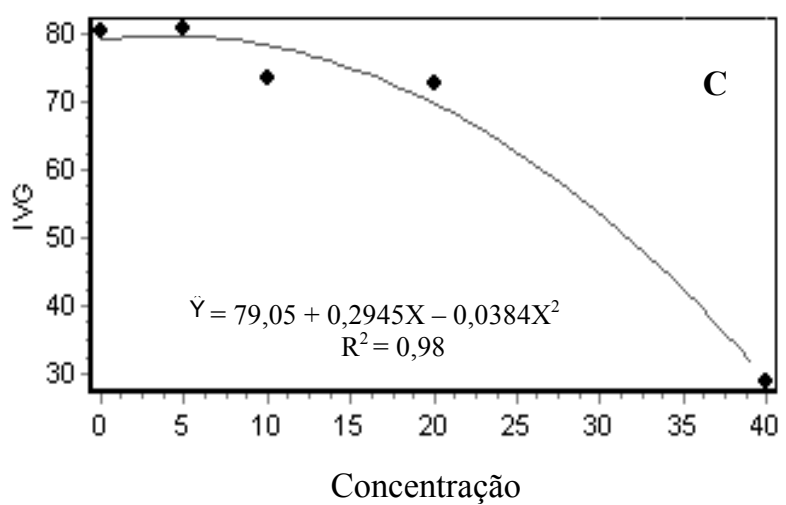

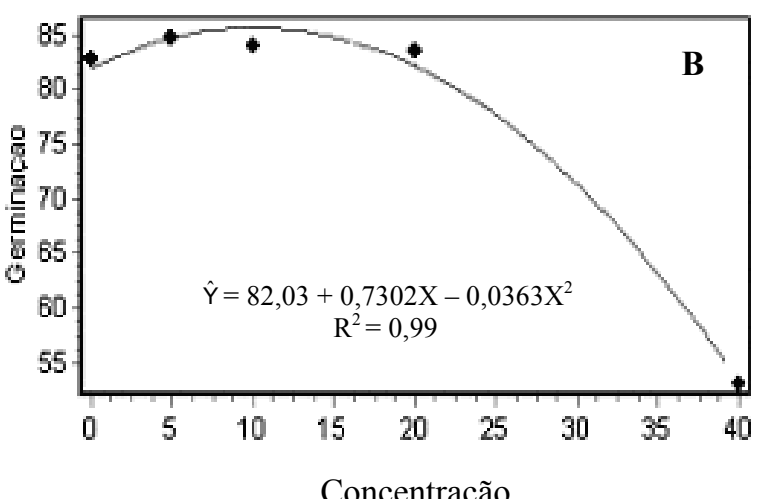

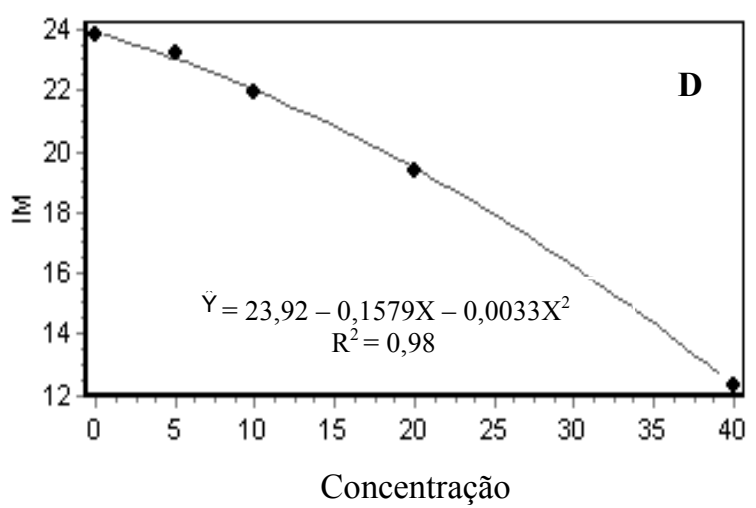

Figura 1 - Gráficos das curvas ajustadas e das médias observadas para as variáveis primeira contagem (A), germinação (B), índice de velocidade de germinação (IVG) (C) e índice mitótico (IM) (D) para sementes de alface tratadas com diferentes concentrações do extrato aquoso de espinheira-santa (M. ilicifolia).

Além do efeito citotóxico, uma análise qualitativa sugeriu um possível efeito genotóxico do extrato de espinheira-santa, uma vez que o extrato na concentração de $40 \mathrm{mg} / \mathrm{mL}$ provocou alterações cromossômicas como pontes anafásicas (Figura 3). Teixeira e Vicentini. (1997), através de ensaio biológico, também verificaram a potencialidade genotóxica de Maytenus ilicifolia sobre os discos imaginais de Drosophila melanogaster.

Camparato et al. (2002), em análises de células meristemáticas de bulbos de cebola (Allium cepa L.), verificaram que concentrações mais elevadas de extrato de espinheira-santa e de pata-de-vaca (Bauhinia candicans Benth.) promoveram redução no índice mitótico, mas não o surgimento de alterações cromossômicas. 


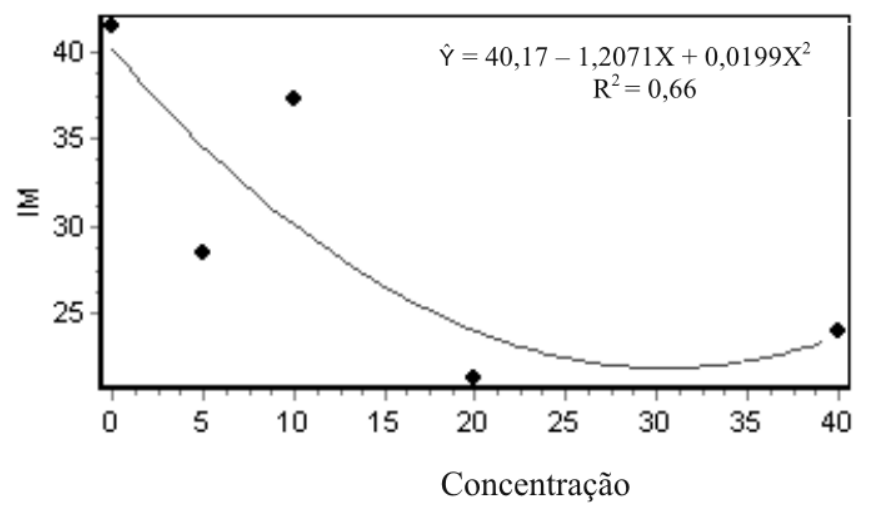

Figura 2 - Gráfico da curva ajustada e das médias observadas para a variável índice mitótico (IM) em sementes de cebola tratadas com diferentes concentrações do extrato aquoso de espinheira-santa (M. ilicifolia).
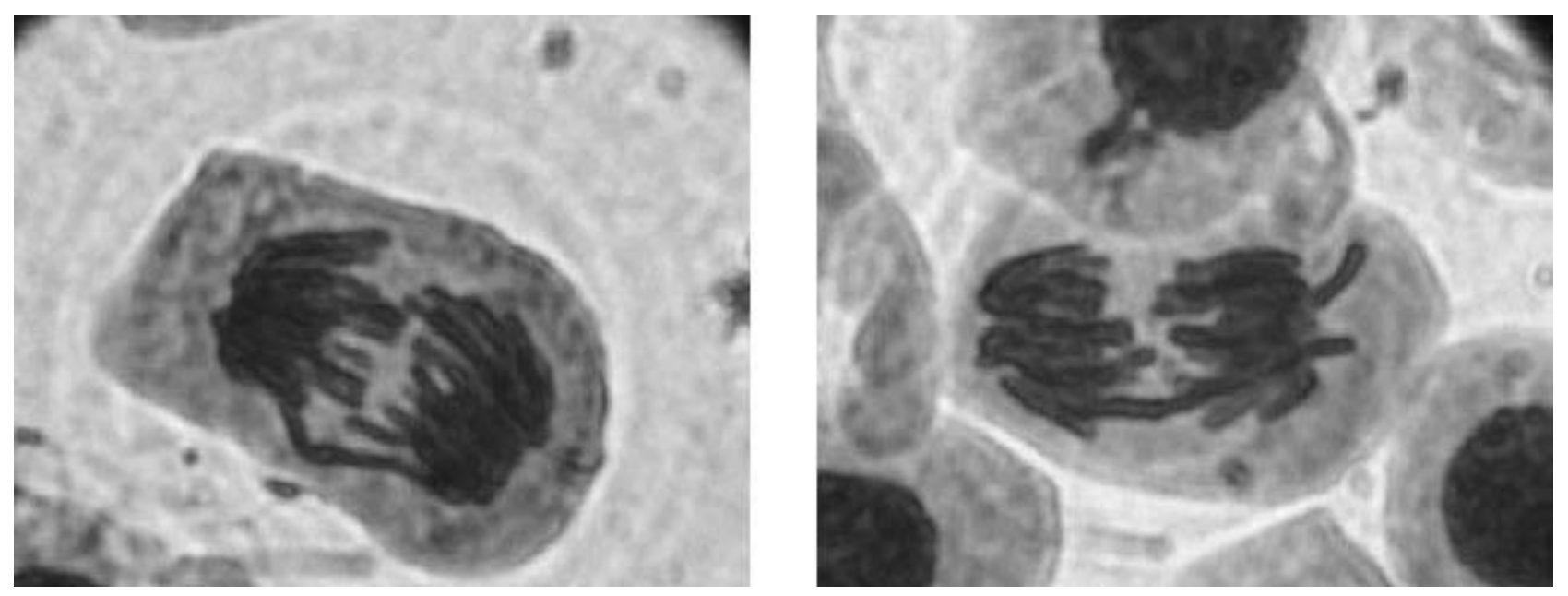

Figura 3 - Células meristemáticas de cebola, apresentando pontes anafásicas, na concentração de $40 \mathrm{mg} / \mathrm{mL}$ do extrato aquoso de espinheira-santa (M. ilicifolia) (400x).

A análise qualitativa dos fitoquímicos mostrou que a espinheira-santa contém em suas folhas saponinas, taninos e flavonas. Rice (1984) relata que os fitoquímicos podem ser encontrados em todos os órgãos vegetais: caules, folhas, raízes, flores e inflorescências, frutos e sementes. Entretanto, a grande maioria dos pesquisadores tem utilizado folhas como principal fonte dessas substâncias. De acordo com Silva (2004), as saponinas, que são terpenóides glicosados, são substâncias envolvidas diretamente em efeitos alelopáticos. Os taninos possuem a propriedade de se ligar a proteínas, formando precipitados irreversíveis, atuando como inibidores de bactérias nitrificadoras, o que pode acarretar efeitos alelopáticos diretos no solo (Rice, 1984). As flavonas, segundo Rice (1992), apresentam efeitos alelopáticos em altas concentrações, sendo capazes de inibir o crescimento de plantas e fungos.

\section{Conclusões}

- O extrato aquoso de M. ilicifolia apresenta efeito alelopático sobre sementes de alface e efeito citotóxico sobre sementes de alface e de cebola.

- O potencial alelopático das folhas de $M$. ilicifolia pode ser explicado pela presença de saponinas, taninos e flavonas.

\section{REFERÊNCIAS}

1. ALMEIDA, F.S. A alelopatia e as plantas. IAPAR, Circular, v.55, 62p, 1993.

2. BRASIL. Ministério da Agricultura e Reforma Agrária. Divisão de Laboratório Vegetal. Regras para análise de sementes. Brasília. 1992.365p. 
3. CAMPARATTO, M.L.; TEIXEIRA, R.O.; MONTOVANI, M.S.: VICENTINI, V.E. Effects of Maytenus ilicifolia Mart. ex Reiss. and Bauhinia candicans Benth. infusions on onion root-tip and rat bone-marrow cells. Genetics and Molecular Biology, v.1, n.25, p.85-89, 2002.

4. CHOU, C.H.; KUO, Y.L. Allelopathic exclusion of understory by Leucaena leucocephala (Lam.). Journal of Chemical Ecology, v.12, n.1, p.1434-1448, 1986.

5. FALEIROS, I.C.F. Efeito antiulcerogênico de frações hexânicas das folhas de Maytenus ilicifolia (Espinheira-santa). In: Simpósio de Plantas Medicinais do Brasil, XII, Curitiba-PR, 1992. Anais do XII Simpósio de Plantas Medicinais do Brasil. p.42.

6. FERREIRA, A.G.; AQUILA, M.E.A. Alelopatia: uma área emergente da ecofisiologia vegetal. Revista Brasileira de Fisiologia Vegetal, v.12, n.1, p.175-204. 2000.

7. GÓRNIK, K.; DECASTRO, R.D.; LIU, Y.; BINO, R.J.; GROOT, S.P.C. Inhibition of cell division during cabbage (Brassica oleracea L.) seed germination, Seed Science Research, v.7, p.485-492. 1997.

8. GUERRA, M.; SOUZA, M.J. Como Observar Cromossomos: um guia de técnica em citogenética vegetal, animal e humana. São Paulo: Funpec, 2002. 131p.

9. LORENZI, H. Plantas Medicinais no Brasil, São Paulo: Plantarum, 2002.512p.

10. MACHADO,A.A.; CONCEIÇÃO, A.R. WinStat - Sistema de Análise Estatística para Windows. Versão Beta. Universidade Federal de Pelotas, 2005.

11. MAGALHÃES, P.M. Agrotecnologia para o cultivo de espinheira-santa. Campinas: CPQBA-UNICAMP. Campinas: RZM, 2002.12p.

12. MEDEIROS, A.R.M. Alelopatia: importância e suas aplicações. Horti Sul. v.1.n.3. p.27-32,1990.

13. NUNES, A.P.M.; ARAUJO, A.C. Ausência de genotoxi- cidade do esteviosídeo em E. coli. In. Semana de Iniciação Cientifica da UERJ, X, 2003, Rio de Janeiro, Anais da X Semana de Iniciação Cientifica da UERJ, 2003.p.15.

14. PIRES, N.M.; PRATES, H.T.; PEREIRA, I.A.; OLIVEIRA, R.S.; FARIA, T.C.L. Atividade alelopática da leucena sobre espécies de plantas daninhas. Scientia Agrícola. v.58, n.1, p. 61-65, 2001.

15. PRATES, H.T.; PAES, J.M.V.; PIRES, N.M.; PEREIRA, I.A.; MAGALHÃES, P.C. Efeito do extrato aquoso de leucena na germinação e no desenvolvimento do milho. Pesquisa Agropecuária Brasileira, v.35, n.1, p.909-914, 2001.

16. RICE, E.L. Allelopathy. 2ed, New York: Academic Press, 1984.

17. RICE, E.L. Allelopathic effectson nitrogen cycling. Allelopathy: basic and applied aspect. London: Chapman \& Hall. 1992.

18. RODRIGUES, F.C.M.P.; LOPES, B.M. Potencial Alelopático de Mimosa caesalpinaefolia Benth sobre sementes de Tabebuia alba (Cham.) Sandw. Floresta e Ambiente. v.8, n.1, p.130-136, 2001.

19. SILVA, F.M. Verificação da eficácia dos bioensaios com extratos aquosos no diagnóstico de potencial alelopático: contribuição ao estudo de espécies nativas brasileiras. Porto Alegre, 2004. 142p. Tese (Mestrado em Botânica) - UFRGS.

20. SOUZA, S.A.M.; STEIN, V.C.; CATTELAN, L.V.; BOBROWSKI, V.L.; ROCHA, B.H.G. Utilização de sementes de alface e de rúcula como ensaios biológicos para avaliação do efeito citotóxico e alelopático de extratos aquosos de plantas medicinais. Revista de Biologia e Ciências da Terra. v.5, n.1, p.3-9, 2005.

21. TEIXEIRA, R.O; VICENTINI, V.E.P. Estudo da mutagenicidade de plantas In. Congresso Brasileiro de Genética,

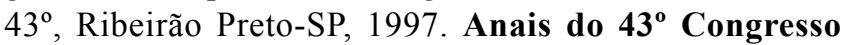
Brasileiro de Genética, 1997. p.115. 